\title{
EUROPEAN SURFACE PRESSURE PATTERNS FOR MONTHS WITH OUTSTANDING CLIMATIC ANOMALIES DURING THE SIXTEENTH CENTURY
}

\author{
JUCUNDUS JACOBEIT \\ Universität Würzburg, Geographisches Institut, \\ Am Hubland, D - 97074 Würzburg, Germany \\ HEINZ WANNER \\ Universität Bern, Geographisches Institut, \\ Hallerstrasse 12, CH - 3012 Bern, Switzerland \\ GERHARD KOSLOWSKI \\ Kurt-Schumacher-Strasse 95, D - 21629 Neu Wulmstorf, Germany \\ MARTIN GUDD \\ Adolf-Kolping-Strasse 1, D - 55411 Bingen-Büdesheim, Germany
}

\begin{abstract}
Monthly mean surface pressure patterns in the European area are reconstructed for those winter and summer seasons of the 16th century with outstanding climatic anomalies being either widespread over Europe or remarkably intensive in some European regions. From the available documentary information about weather characteristics and their sequences, it proved possible to infer prevalent processes of lower tropospheric advection of typical air masses and to assess the position and strength of major surface pressure centres on a monthly scale. For comparison with modern pressure patterns, monthly mean sea level pressure (SLP) grids from the 20th century have been selected for seasons with similar climatic anomalies. There are broad coincidences between these pressure patterns of the 16th and the 20th centuries except for cold summer seasons. Finally, results from the 16th century are discussed in terms of circulation dynamics (different phases of the North Atlantic Oscillation (NAO) in winter, decreasing frequency of anticyclonic ridging in summer).
\end{abstract}

\section{Introduction}

The European climate of the 16th century, with its extremes such as the warm summers in its first four decades and the very cold winters in its last four decades, marks the beginning of the second Little-Ice-Age-type event with remarkable glacier advances leading to maximum ice extensions in the European Alps between 1600 and 1660 (Holzhauser and Zumbuehl, 1996). These decadal-scale climatic fluctuations must find the special interest of synoptic climatology. 
However, precise meteorological data are very scarce during this period. This makes a careful synoptic analysis very difficult. In fact, only multi-proxy data and descriptive information from historical weather observations have been used for reconstruction (see this volume).

From modern surface pressure, temperature and precipitation data it is known that the North Atlantic-European area is subject to characteristic climate modes in connection with the so-called North Atlantic Oscillation (NAO) (Walker, 1924; Van Loon and Rogers, 1978; Lamb and Peppler, 1987; Moses et al., 1987; Wanner et al., 1997). The positive mode of the NAO is characterized by a wellmarked pressure gradient between the Azores High and the Icelandic Low leading to a strong zonal flow which is connected with the occurrence of wet winters over the northern part of Europe and rather warm and partially dry winters over the southern part. If this pressure gradient is reduced with a weakened zonal flow, the NAO-Index (defined as the difference of the normalized pressure deviations for the Azores and Iceland) decreases to negative values. An important negative mode is achieved with pressure gradient reversals. This situation is characterized by a strong blocking of the westerlies and a meridional flow pattern, high pressure with warm winters over Iceland and a north to northeasterly flow with extremely cold winters over Scandinavia and central Europe. The question is raised whether the climatic fluctuations of the 16th century are linked to pressure patterns representing different modes of the NAO - possibly similar to the Late Maunder Minimum (Wanner et al., 1995). Do they also represent climatic cycles with periods of about 30 years similar to those of the 19th and 20th centuries (Wanner et al., 1997)?

Since documentary climatic data often only deal with remarkable or extreme events (Glaser, 1996), we are not able to analyze the complete sequence of climatic situations during the 16th century. Rather it is indicated that months or seasons with outstanding climatic conditions, such as warm or cold, wet or dry anomalies should be concentrated on. At the same time, it is reasonable to focus on winter and summer conditions since data from the transitional seasons are less numerous and often quite ambiguous. Thus, we aim at reconstructing monthly mean surface pressure patterns from documentary information on climatic conditions during summer and winter months of the 16th century with outstanding climatic anomalies.

These pressure patterns will be studied, in a further step, with respect to possible links with the 20th century. Types of pressure patterns from the 16th century are compared with modern types of pressure patterns associated with similar climatic anomalies, in order to learn whether there are broad coincidences or clear-cut differences between historical and modern pressure patterns during periods of anomalous climate. Finally, results from the 16th century are discussed in terms of major synoptic modes (NAO) and dynamical processes (variations in the ocean-atmospheric circulation) governing the climate of Europe and the North Atlantic area. 


\section{Data and Methods}

The main part of the information concerning the climate of the 16th century has been drawn from two historical climate data banks, EURO-CLIMHIST (University of Berne, see Pfister et al., 1994) and HISKLID (University of Würzburg, see Glaser, 1996). Additional unpublished information has been made available for the British Isles (J. Kington), the Iberian Peninsula (J. Martin-Vide, M. Barriendos), Italy (D. Camuffo), Hungary (L. Rácz), and south-western USSR (A. Bokwa). Most of the material consists of descriptive information related to remarkable weather phenomena on a regional scale. Continuous transformations into monthly temperature and precipitation indices (see this volume) are only available for Germany and Switzerland. Observations of wind direction and strength, highly valuable for the reconstruction of atmospheric circulation patterns, are only available for north-western Germany and Denmark during the last two decades of the 16th century (Pfister et al., this volume).

By combining all this information (Glaser et al., this volume) we obtain a selection of winter and summer seasons with outstanding climatic anomalies being either widespread over Europe or remarkably intensive in some European regions (Table I). Since historical man's perception of climate primarily refers to anomalous conditions, we may suppose that this selection is based upon reliable records of anomalies and constitutes some representative samples for the 16th century. Concerning the denotation of seasonal anomalies in Table I, it should be mentioned that winter conditions are correctly described by temperature (warm or cold, respectively) whereas the summer anomalies may sometimes be determined more by rainfall deviations. The 'bad' summer of 1588, for example, was primarily a wet season, at least in central Europe (Glaser, 1996); also a striking feature of the warm summers from Table I was extraordinary dryness. Thus, the summer anomalies have been selected according to both temperature and precipitation deviations.

Table I

Seasons with outstanding climatic anomalies during the 16th century according to Glaser et al. (this volume)

\footnotetext{
warm winters: $\quad 1530,1566,1577$

cold winters: $\quad 1514,1561,1565,1569,1571,1573,1587,1595$

warm summers: $\quad 1503,1516,1534,1536,1540,1590$

cold summers: 1542,1588
}

The fact that cold winters have the largest sample size should not be interpreted with respect to climate. It simply reflects that severe winter conditions have the 
most impressive effect on historical man, thus inducing skewness within the distribution of outstanding anomalies. However, we do not intend to deal with frequency analyses - the present study aims at reconstructing pressure patterns for selected anomalies, and Table I gives the most appropriate samples, according to documentary data in the European context.

The reconstruction of surface pressure patterns has been performed on a monthly basis using all the available resources about weather characteristics and their sequences across the whole area under consideration. It is possible, in general, to infer from this information the prevalent processes of lower tropospheric advection of typical air masses and from the distribution of these main air flows, we are able to assess the position and strength of major surface pressure centres that are governing the lower tropospheric circulation on a monthly scale. As a result, we obtain monthly surface pressure patterns with major centres and attendant flow characteristics. However, due to the descriptive quality of data sources, no absolute values of pressure and pressure gradients could be established.

This manual procedure is strongly favoured by dealing with anomalous seasons which are known to develop distinct patterns of atmospheric circulation. Thus, warm winters are mostly characterized by the advection of maritime air masses from the south-west to west, concomitant with positive modes of the NAO. Cold winters, at least in central Europe, are characterized by frequent outbreaks of Arctic air masses either from the north (high pressure over Iceland-Norway) or from the east (extension of the Siberian High towards Scandinavia). Distinction between these major modes is possible in terms of ice production intensity in the western Baltic (very high intensities are linked with persistent advection of continental air from northern Russia, amplifying the latent heat flux from the sea to the very dry air masses; lower intensities of ice production occur with somewhat moister air masses being advected from the north).

During summer, there are different kinds of anticyclonic ridges (with zonal, diagonal or meridional orientation) for the occurrence of warm and dry conditions, whereas cold summers are mostly linked with cyclonic influences (either in a zonal mode or with a trough pattern). Thus, it proved to be a reasonable procedure to reconstruct surface pressure patterns from the documentary source information about outstanding climate anomalies.

For comparison with modern pressure patterns we used the gridded National Center for Atmospheric Research (NCAR) SLP data set from 1899 to 1994, taking into consideration all months with thermal anomalies similar to those from the 16th century (Jacobeit, 1997). These SLP grids, analyzed from instrumental data, have been averaged on a monthly basis and thus include all particular daily patterns and not only those corresponding to the typical configuration on the monthly scale. In the reconstructed patterns from the 16th century, however, intermediate deviations from the dominant configuration must be neglected, thus maps represent general prevalent conditions rather than real monthly means. 
Nevertheless, comparisons between the 16th and the 20th centuries should not be affected if we concentrate on the basic characteristics of the pressure patterns.

The reconstructed maps from the 16th century are not, of course, derived objectively as, for example, the historical SLP grids from Jones et al. (1999) for the period since 1780; no adequate data for such operations are actually available for the 16th century, and it is highly questionable if sufficient data would ever be available. The general method largely compares with that applied to the Late Maunder Minimum (Wanner et al., 1994) and obviously is dependent on the status of information for these historical periods. Thus, remaining uncertainties in the reconstructed pressure patterns, due to insufficient information, might be reduced if additional data with adequate resolution (especially from northern Europe) would become available in the future.

\section{Results}

\subsection{MAPS}

The reconstructed monthly surface pressure patterns for the anomalously warm and cold winter and summer seasons of Table I, respectively, are shown in Figures 1-4. In the case where prevailing patterns of consecutive months were almost identical, only one map has been reproduced; for the 1573 winter, for example, the map in Figure 2 represents the prevailing pattern for the whole season; maps for particular months would not give any further information.

Sometimes one month occurs with a pressure pattern differing completely from those of the greater part of the season and apparently opposing the general climatic character of that season. For example, February 1571 (Figure 2) does not continue the cold air advection over central Europe associated with a Fennoscandian high that prevails during the preceding months; coldness just survives in the southern part of central Europe (Glaser, 1996), whereas warm air advection to the north causes less severe ice conditions in the western Baltic for this season (Koslowski and Glaser, 1999). With regard to summers, the warm season of 1590 only starts in June in southern central Europe, whereas to the north we still have a cyclonic wave pattern during this first summer month (Figure 3).

Summing up, the reconstructed pressure patterns allow us to identify the main types according to the seasonal anomalies:

a) Warm winter seasons of the 16th century (Figure 1) reveal two basic patterns. The first one has a main low pressure system near Iceland with warm air advection from the south-west or west-south-west towards Europe; the maps for January 1577 and January 1530 clearly represent this type. The second pattern is characterized by a westerly flow across central Europe in connection with a strong high pressure system centred over Iberia; this kind of flow pattern may be 

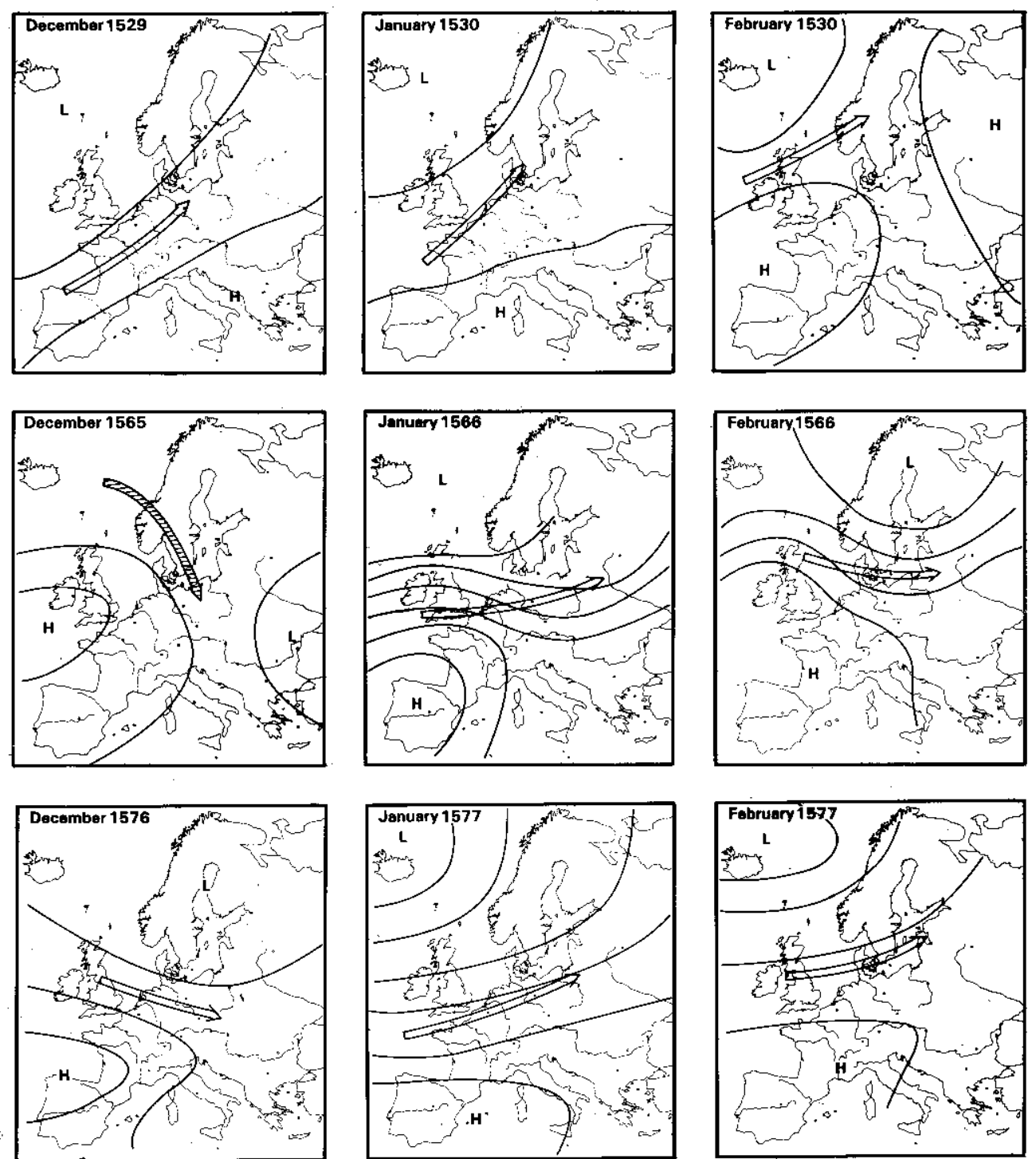

Figure 1. Reconstructed monthly surface pressure patterns for the warm winter seasons according to Table I.

white/hatched/black arrows indicate advection of warm/moderate/cold air masses

seen most clearly in January 1566.

b) Cold winter seasons of the 16th century (Figure 2) are mainly caused by high pressure in the Fennoscandian area with cold air advection from the east or 

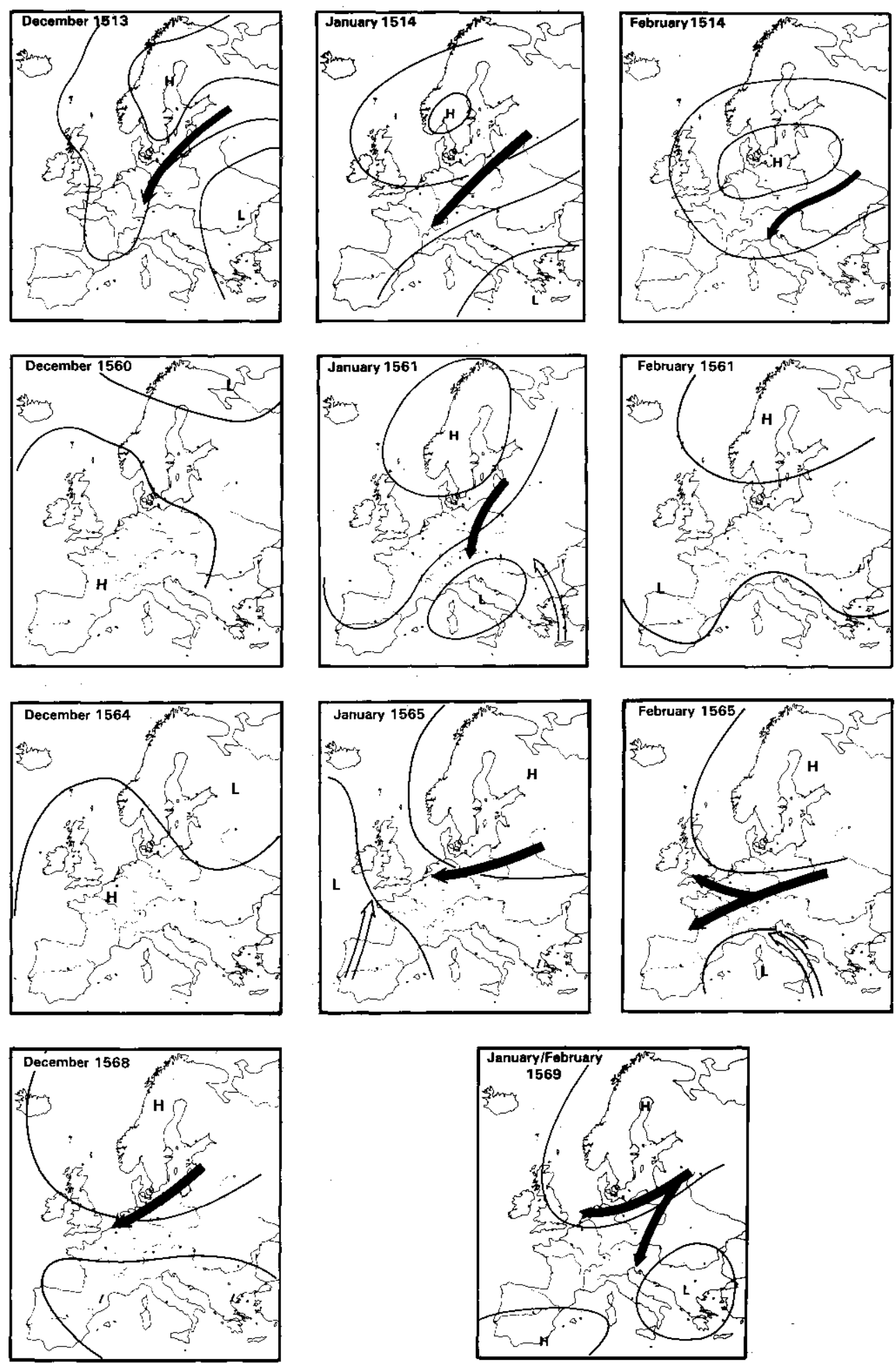

Figure 2. As in Figure 1 but for cold winter seasons 

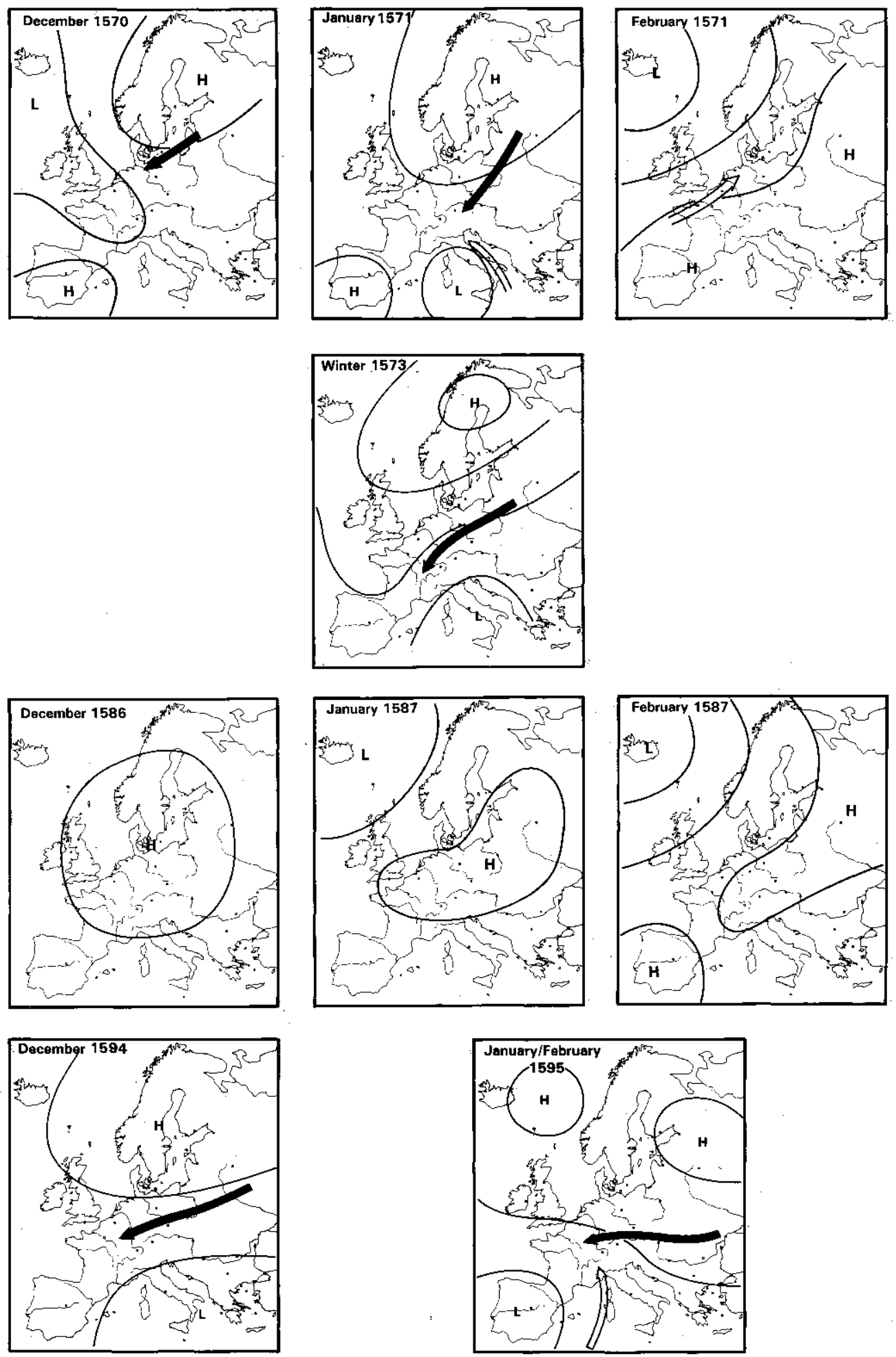

Figure 2. (Continued) 

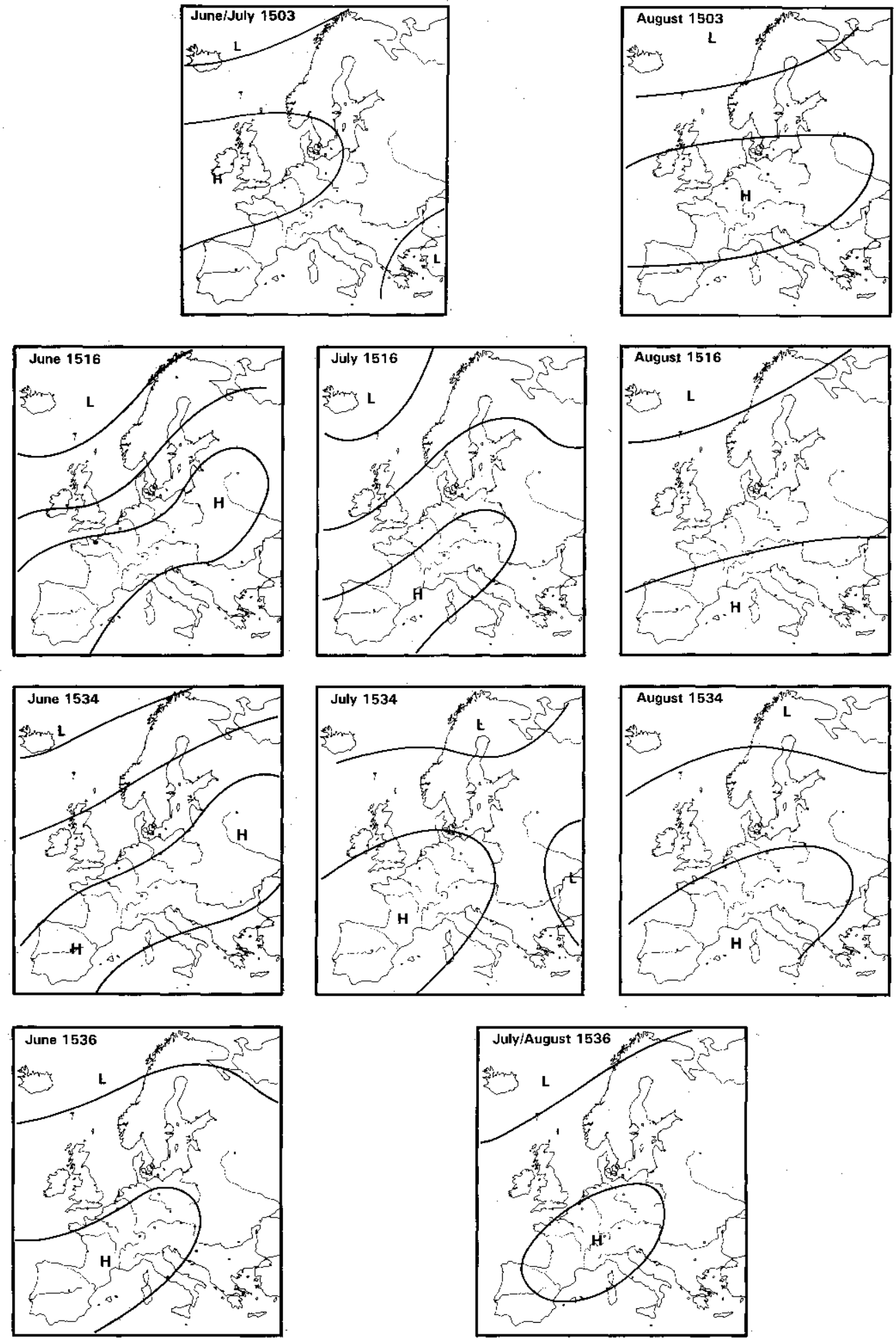

Figure 3. As in Figure 1 but for warm summer seasons 

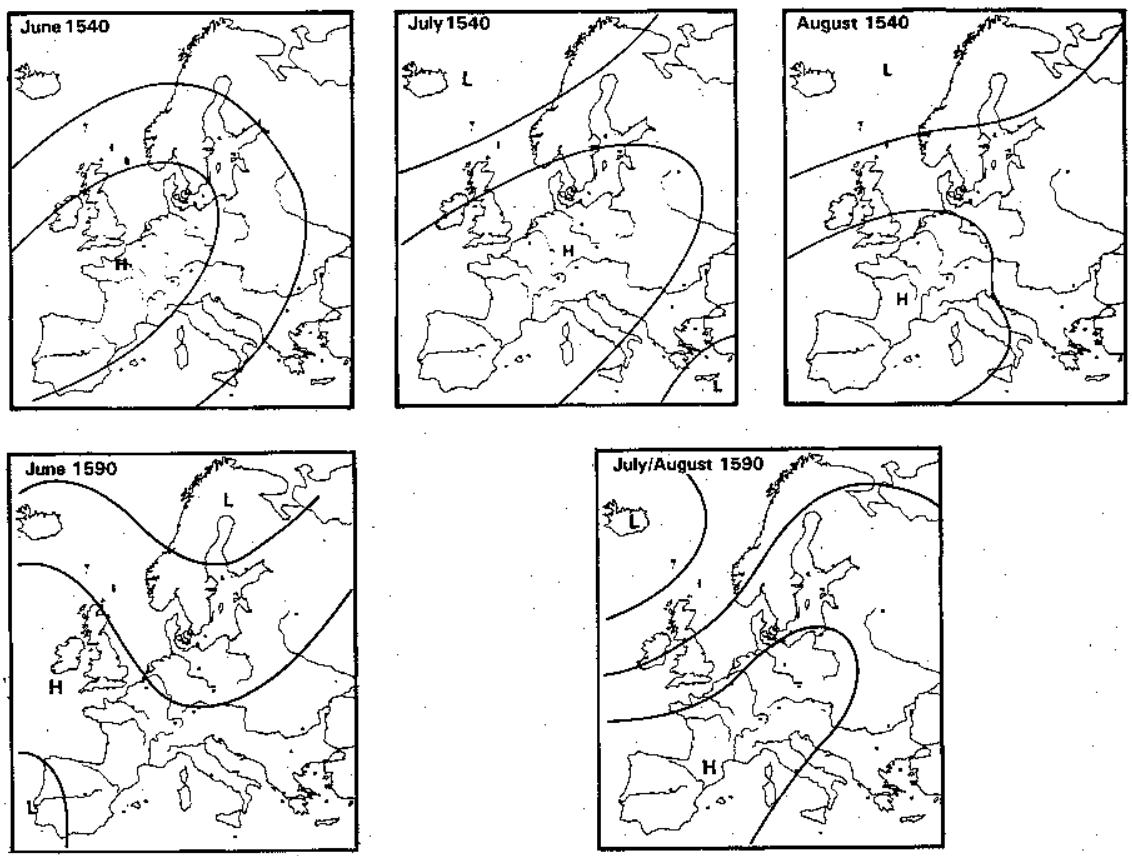

Figure 3. (Continued)
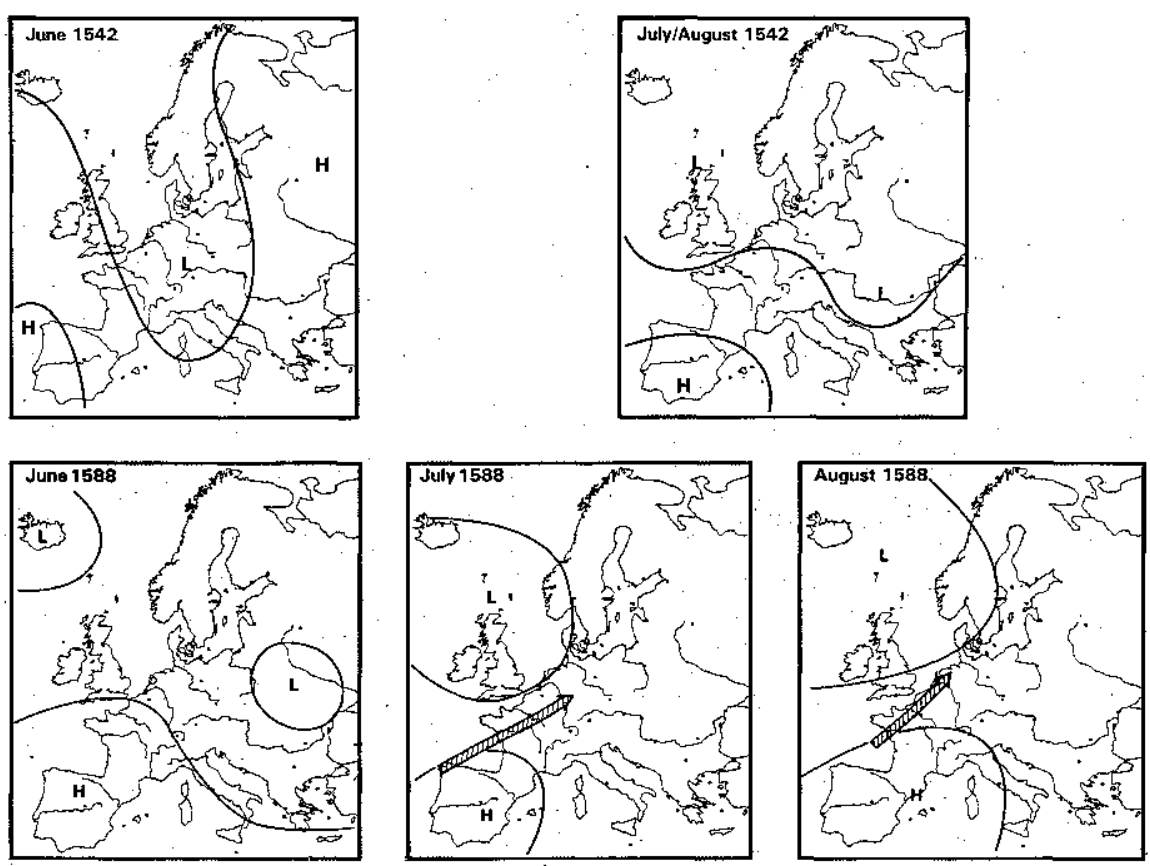

Figure 4. As in Figure 1 but for cold summer seasons 
north-east; among the frequent cases of this type the maps of January 1565, January/February 1569, January 1571 and winter 1573 illustrate typical examples. Sometimes the high surface pressure extends farther westward: a certain tendency for this occurs during January 1514 and the map for January/February 1595 even shows a second anticyclonic centre east of Iceland, resulting in a northerly flow over north-western Europe and indicating an actual reversal of the NAO (North Atlantic pressure gradient directed southward).

Sometimes the centre of high pressure is not situated over Scandinavia or the North Atlantic but in somewhat lower latitudes near or over central Europe (for example, February 1514, December 1586 , January 1587 ). With regard to 1587 , the NAO even seems to be in a positive mode with the circulation representing a transitional state between zonal and meridional patterns.

c) Warm summer seasons of the 16th century (Figure 3) are characterized by zonal or diagonal ridges of high pressure over central Europe which are very often connected to the Azores High. More frequent are those with a south-west to north-east orientation, and a particularly well-developed example occurred during June and July 1540 . Sometimes the ridge retreats farther to the south-east with cyclonic influence over the British Isles (e.g. July/August 1590), sometimes an anticyclonic bridge occurs between two centres of high pressure over Iberia and eastern Europe (e.g. June 1534). With zonal ridges of high pressure, warm summer conditions do not extend as far northward, and Scandinavia is influenced by subpolar low pressure (see, for example, August 1503).

d) Cold summer seasons of the 16th century (Figure 4) may be described by three different types of configuration: firstly, a central European trough (June 1542); secondly, a small-amplitude wave pattern with embedded cyclonic activity (July/August 1542, June 1588); and a third pattern occurs with moderate advection of Atlantic air masses ahead of a low pressure system over the British Isles (July and August 1588).

\subsection{LINKS WITH THE 20TH CENTURY}

In order to clarify whether there are broad coincidences or main differences between the anomaly patterns of the 16th century discussed in section 3.1 and the corresponding patterns of the 20th century, monthly mean SLP grids from the NCAR data set (1899-1994), selected for seasons with similar climatic anomalies as in the 16th century, have been examined for main types of pressure patterns according to the procedure in the preceding section. Figures 5-8 give North Atlantic/European SLP patterns from particular months representing these main types of the recent century which will be discussed in comparison with the results for the 16th century: 

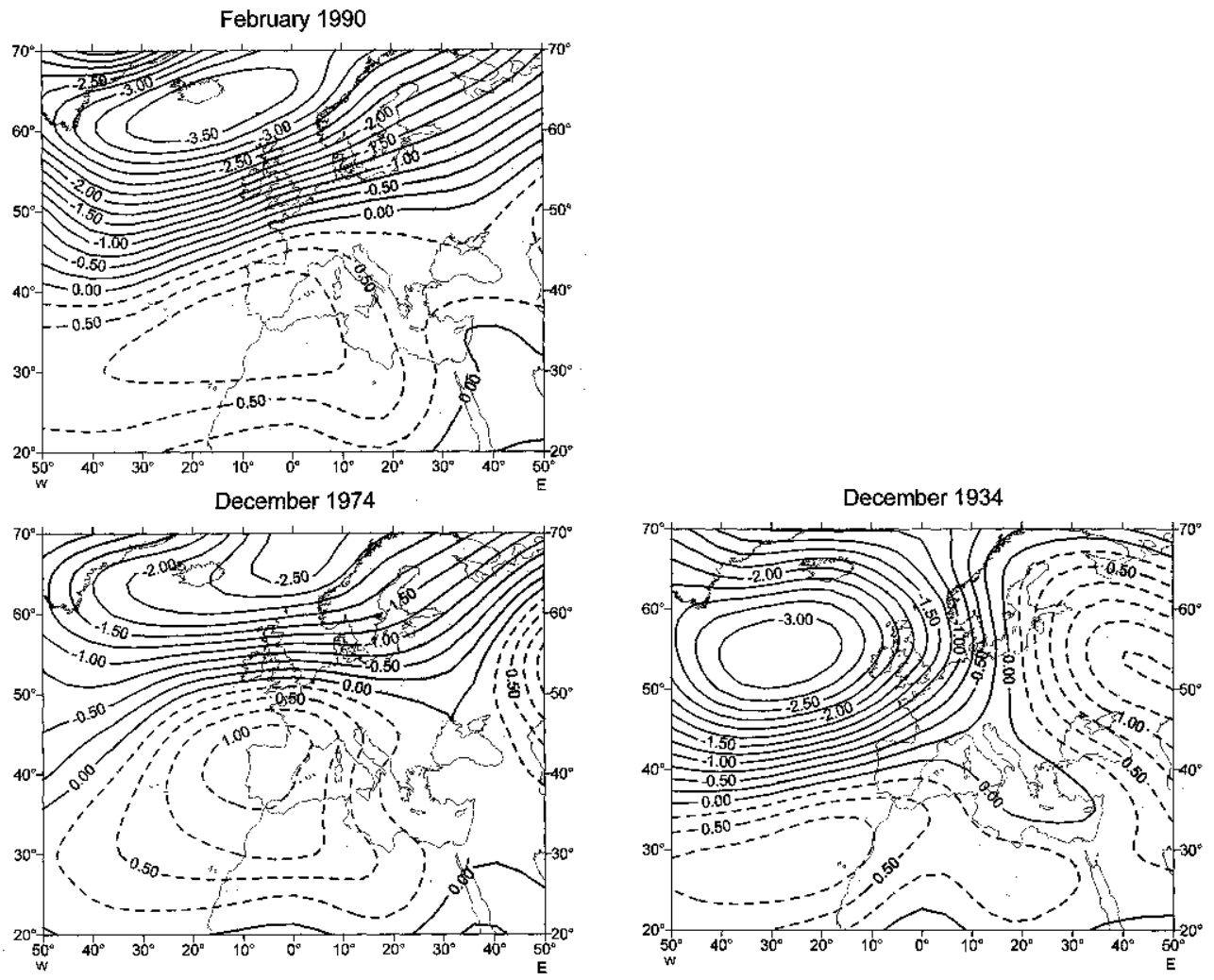

Figure 5. North Atlantic/European normalized SLP patterns (positive values dashed) for particular months representing different types of circulation during warm winter conditions within the modern period 1899-1994

a) For warm winter conditions (Figure 5) we obtain three main types represented by the monthly mean SLP grids of February 1990, December 1974 and December 1934. The former two clearly reproduce the basic types found for the 16th century: a main low pressure system near Iceland with warm air advection from the south-west or west-south-west towards Europe (e.g. January 1577), and a westerly flow type across central Europe in connection with a strong high pressure centre over Iberia (e.g. January 1566). Only the third modern type (December 1934) is not found among the patterns from the 16th century. It is characterized by a central Atlantic low to the west of the British Isles with a southerly flow over central Europe. This type, however, mainly operates during isolated months with warm conditions rather than during seasonally persisting anomalies that have been extracted in the 16th century. 

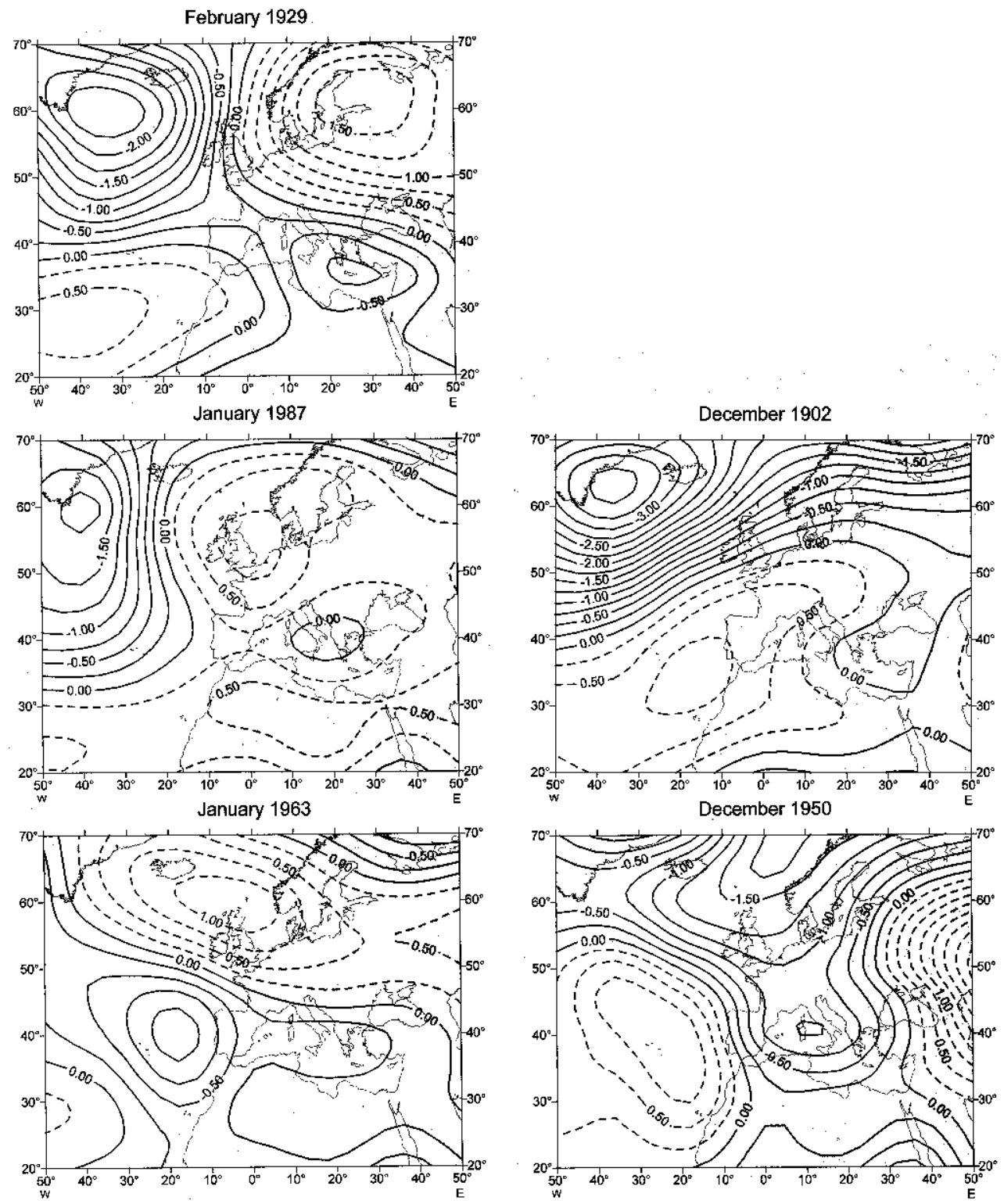

Figure 6. As in Figure 5 but for cold winter conditions

b) Among the main types for modern cold winter conditions (Figure 6) we also find the most important type from the 16th century (high pressure in the Fennoscandian area with cold air advection from the east or north-east). There are many recent analogue cases (for example, the severe European winters of 1940, 1942 and 1947), February 1929 may represent this typical pressure pattern. During the 20th century we have also good examples for more westerly positions of 
high pressure centres: for example, over the North Sea area (see January 1987) or even towards the Icelandic region (see January 1963) in connection with a strong reversal in the NAO (Moses et al., 1987). During the 16th century these different patterns are not clearly recognized: in January 1514 (Figure 2), for example, there is only a certain tendency for high pressure extension towards the British Isles; whilst January/February 1595 matches the NAO reversal of January 1963 , it differs with respect to the direction of flow in the Baltic region (northerly advection in 1963, but an easterly one in 1595). Thus, severe winters in the 16th century seem to have been associated preferably with patterns having distinct easterly components affecting the whole of central Europe.

Recent analogues for the less frequent cases with high pressure concentrating around central Europe (e.g. February 1514, December 1586, January 1587) are not easily found during the 20th century: for instance, although the pressure pattern of December 1902 (Figure 6) has anticyclonicity over central Europe with the NAO in a positive mode, the cold winter conditions were caused primarily by outgoing radiation rather than by advection from the east. Again, modes with easterly components during coldness in winter seem to be the preferred patterns in the 16th century.

The last type from the present century (December 1950) shows a trough pattern over central Europe for which no correspondence has been found during the 16th century. This type, however, is not a prevalent one near the surface, instead it often governs strong winter conditions at the $500 \mathrm{hPa}$ level as, for example, during January 1963 (Jacobeit, 1993).

c) For warm summer conditions of the 20th century we obtain five main types of pressure patterns (Figure 7), four of them being reflected during the 16th century. The first type (a north-east extension of the Azores High with a zonal ridge of high pressure across central Europe and cyclonic influence above Scandinavia) is illustrated by August 1992, and formerly realized, for example, during August 1503. The second type (diagonal ridges of high pressure with south-west to north-east orientation including the British Isles and the southern part of Scandinavia) is illustrated by July 1983, and was also an important type during the 16th century, see, for example, June and July 1540 . The third type (the diagonal ridge shifted somewhat to the south-east with cyclonic influence over the British Isles) is illustrated by June 1935, formerly realized during July and August 1590. The fourth type (an anticyclonic bridge between two centres of high pressure over Iberia and eastern Europe) is illustrated by August 1942, and formerly realized, for example, during June 1534.

There is only one type, represented by July 1994, without historical correspondence in the 16th century: a meridional ridge of high pressure leading to anticyclonic conditions extending to the north of Scandinavia. The reason for this historical absence is not definitely clear: changes in circulation cannot be excluded but, on the other hand, there is no unequivocal evidence. Perhaps, defi- 

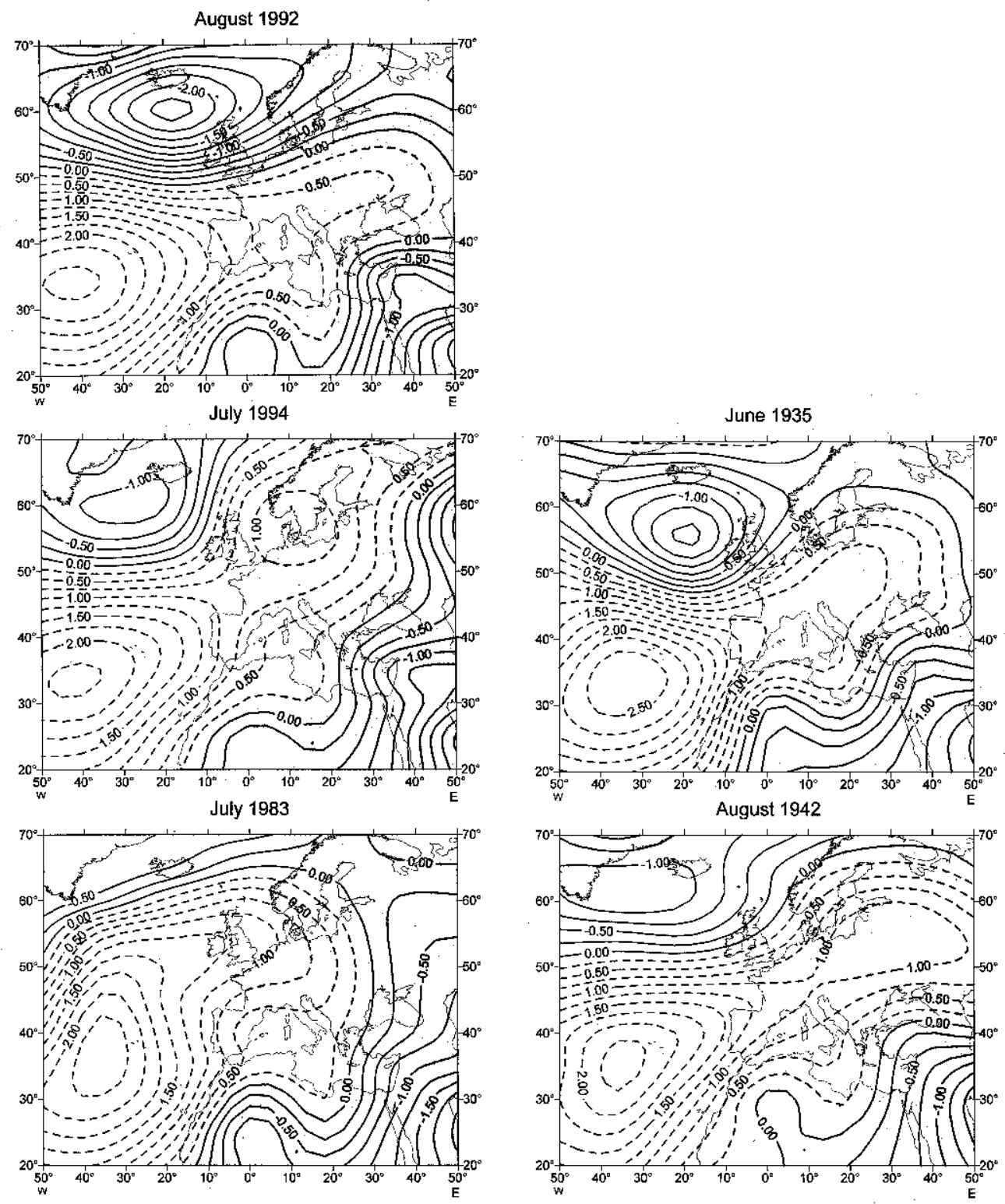

Figure 7. As in Figure 5 but for warm summer conditions

ciencies in data sources might be responsible: thus, the extraordinary summer of 1540 would have been a possible candidate for meridional ridging, but without adequate information, sufficiently resolved in time and space, especially from northern Scandinavia, it has been impossible to infer such types of surface circulation. This unresolved question is waiting for further supplements of information. 

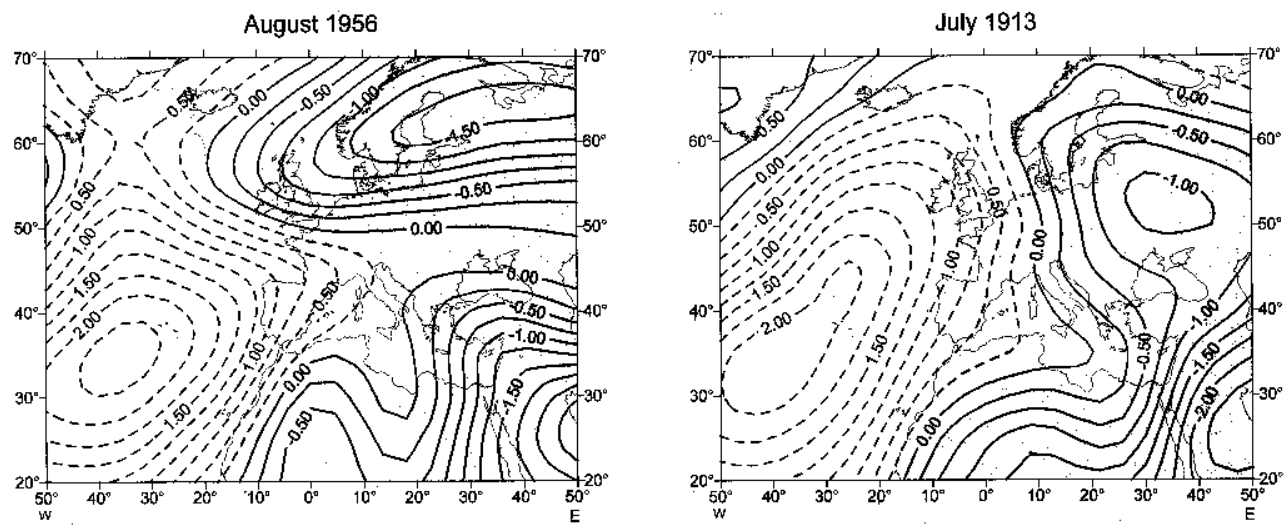

Figure 8. As in Figure 5 but for cold summer conditions

d) For cold summer conditions of the 20th century we obtain two main types of pressure patterns (Figure 8). The first one shows zonal flow across central Europe south of a deep low over Scandinavia (August 1956). The second type has northerly to north-westerly advection over central Europe due to a meridional configuration with high pressure over the eastern North Atlantic (July 1913). Correspondence with the 16th century is quite weak in this case: a meridional pattern still occurs in June 1542, but the small-amplitude wave patterns (July/August 1542, June 1588), derived as typical configurations, will hardly persist when calculating real monthly means (as during the present century). Finally, the situation with a low pressure system over the British Isles (July and August 1588) might be explained by internal changes of air mass qualities. During the last four decades of the 16th century sea surface temperatures (SSTs) of the eastern North Atlantic were probably lower than nowadays, thus inducing somewhat cold or wet summer conditions ahead of the low over the British Isles. During the present century, with higher SSTs, this configuration does not occur among the 'bad' summers.

\subsection{OBSERVED DYNAMICS}

In order to integrate the selected anomalies of the 16th century into an overall framework of climate evolution, we may look, concerning the winter season, at the ice conditions in the western Baltic. Koslowski and Glaser (1999) have extended an ice winter severity index for this region back to the year 1501 
indicating periods of increased and reduced severity, respectively, during the 16th century. There are two persisting periods of an increased ice winter severity: 1554-1576, with a mean value twice as large as the reference value for 19011960; and 1593-1630 extending well into the 17th century. The other periods (1501-1553 and 1577-1592) are characterized by a reduced ice winter severity with mean index values closely similar to the reference value for 1901-1960. Other documentary data from Switzerland (Pfister, 1995), Germany (Glaser, 1996) and further sites in central Europe (see this volume) also indicate two major periods of winter coldness during the second half of the 16th century, separated by a short recovery of roughly one and a half decades. The remarkably cold winter seasons extracted for this analysis (Table I) originate, in most cases, from these generally colder periods, only the singularly great winters of 1514 and 1587 occurred during periods of generally less severe conditions.

Since there is an empirical relation during the modern period, 1879-1992, between ice winter severity in the western Baltic and the frequency of concurrent events of weak westerly flow over the eastern North Atlantic (Koslowski and Loewe, 1994), it is possible to assess the frequency of weak westerly flow during the 16th century from the historical ice winter severity in the western Baltic (Koslowski and Glaser, 1999). According to these assessments, the zonal circulation over the eastern North Atlantic was probably enhanced during the periods 1521-1553 and 1577-1592 (positive mode of the NAO) whereas during the period 1554-1576 and after 1592, westerly flow was often weakened indicating negative values of the NAO index and a more frequent incidence of blocking situations. This is in general accordance with the reconstructed maps from section 3.1. It should be mentioned, too, that singularly cold winter seasons within periods of generally enhanced zonal circulation often have a pressure pattern without complete blocking (transitional circulation mode); for the severe winter of 1587 even a continued positive mode of the NAO seems to be indicated (Figure 2).

With regard to the summer seasons, there is an overall trend of declining European temperatures throughout the 16th century (Bradley and Jones, 1995b; Pfister, 1995) leading to the fact that five out of six warm summer seasons extracted for this analysis (Table I) originate from the first four decades of the 16th century. In view of the reconstructed surface pressure patterns from section 3.1 , this should be linked to a decreasing frequency of anticyclonic ridging from the Azores centre of action towards continental Europe. Such changes in preferred modes of circulation give rise to think about factors governing state and evolution of the climate system.

\subsection{FORCING FACTORS}

Deriving dynamical explanations for the observed decadal, or even century-scale, climatic variability in the 16th century is largely restricted by insufficient knowledge and data for this period. We may only look at important forcing factors 
such as volcanic eruptions, solar activity and internal variations of the climate system accepting that an anthropogenic influence can be excluded.

According to Simkin et al. (1981), there were some strong volcanic events during the 16th century which are thought to have injected material into the stratosphere:

- St. Helens (USA):

- Hekla (Iceland):

- Arenal (Costa Rica):

- Cotopaxi (Ecuador):

- Agua de Pau (Azores Is.):

- San Salvador (El Salvador):

- Kalut (Indonesia):

- Quilotoa (Ecuador):

Surface cooling effects on climatic time scales, however, may arise primarily if several strong eruptions accumulate airborne material within a couple of years or even over decades. The time series of various volcanic indices assessing the overall back-ground of volcanic influences on climate do not indicate continuously high values for the 16th century (Bradley and Jones, 1995a). Accordingly, volcanic forcing does not seem to be a major factor in the climate history of the 16th century.

Solar activity variations are reflected in tree-ring ${ }^{14} \mathrm{C}$ and in ice-borne ${ }^{10} \mathrm{Be}$. According to Eddy and Oeschger (1993), as well as Lean and Rind (1996), the 16 th century marks a period of solar activity recovering from the Spörer Minimum of the 15th century before declining again to the Maunder Minimum of the 17th century. However, the implied changes of solar irradiance are generally small and consequently the climate variance attributable to solar forcing is small, relative to the internally generated variance of the climate system (Stuiver and Braziunas, 1995).

This internal variability is closely linked, on the decadal to centennial time scale, to ocean dynamics (Stocker, 1996), especially in the North Atlantic where the North Atlantic Deep Water (NADW) formation seems to fluctuate with periods of several decades (Delworth, Manabe and Stouffer, 1993), affecting SST patterns and thereby the atmospheric circulation in the North Atlantic-European region (Palmer and Sun, 1985). With regard to the 16th century, it is conceivable that variations in the thermohaline circulation played a major rule within climatic variability. Further indications for internal variations of the climate system originate from ice core records showing a drop in the $\mathrm{CO}_{2}$ concentration by about 10 $\mathrm{ppm}$ in the late 16th century (Jones, 1996), but further information is still needed to establish a consistent theory of climatic variations within this historical period. 


\section{Conclusions}

The reconstruction of European surface pressure patterns for outstanding climatic anomalies of the 16th century and their comparison with corresponding cases of the 20th century, have indicated that climatic variability during the historical period passed through nearly all the important states known from recent studies but within the distinct evolution of climate that occurred towards the second Little-Ice-Age-type event culminating in the 17th century. Thus, in general, there are broad coincidences between pressure patterns of the 16th and the 20th centuries associated with European climatic anomalies - except for cold summers when different North Atlantic SSTs might cause different effects on resulting European weather characteristics. With regard to the warm summers, there is some uncertainty about the meridional ridge pattern known from recent observations: its absence among the reconstructed patterns of the 16th century might be due either to circulation changes or to incompletenesses in the available data. Furthermore, for cold winter conditions there is a tendency that during the 16th century surface pressure patterns with distinct easterly components are more prevalent than patterns with northerly components. During warm winters, patterns with a positive mode of the NAO are dominant which is in accordance with recent observations.

Comprehensively, the climate of the 16th century is characterized by an overall trend of declining European summer temperatures linked with a decreasing frequency of anticyclonic ridging from the Azores centre of action towards continental Europe. For the winter situation different periods with enhanced (1521-1553, 1577-1592) or weakened westerly flow (1554-1576, after 1592) may be distinguished. Internally generated variance of the climate system in connexion with decadal-scale variations of the thermohaline circulation in the North Atlantic ocean most probably have forced these changes in climate during the 16th century.

\section{References}

Bradley, R.S. and Jones, P.D.: 1995a, 'Records of Explosive Volcanic Eruptions Over the Last 500 Years', in Bradley, R.S. and Jones, P.D. (eds.), Climate Since A.D. 1500, Routledge, London and New York, pp. 606-622.

Bradley, R.S. and Jones, P.D.: 1995b, 'Recent Developments in Studies of Climate Since A.D. 1500', in Bradley, R.S. and Jones, P.D. (eds.), Climate Since A.D. 1500, Routledge, London and New York, pp. 666-679.

Delworth, T.S., Manabe, R.J. and Stouffer, R.J.: 1993, 'Interdecadal Variations of the Thermohaline Circulation in a Coupled Ocean-Atmosphere Model', J. Climate 6, 1993-2011.

Eddy, J.A. and Oeschger, H.: 1993, 'The Role of Solar Output Variations', in Eddy, J.A. and Oeschger, H. (eds.), Global Changes in the Perspective of the Past, Wiley, Chichester et al., pp. 279-294. 
Glaser, R. and Militzer, S. (eds.): 1993, Wetter - Witterung - Umwelt, Aufzeichnungen und Daten aus Franken, Sachsen, Sachsen-Anhalt und Thüringen 1500-1699, Würzburg.

Glaser, R.: 1996, Beiträge zur Historischen Klimatologie in Mitteleuropa seit dem Jahr 1000, Habilitationsschrift Universität Würzburg.

Holzhauser, H. and Zumbuehl, H.J.: 1996, 'To the History of the Lower Grindelwald Glacier During the Last 2800 years - Paleosols, Fossil Wood and Historical Pictorial Records - New Results', Z. Geomorph. N.F. Suppl. 104, 95-127.

Jacobeit, J.: 1993, 'Regionale Unterschiede im atmosphärischen Zirkulationsgeschehen bei globalen Klimaveränderungen', Die Erde 124, 63-77.

Jacobeit, J.: 1997, 'Atlantisch-europäische Bodenluftdruckfelder ombrothermisch anomaler Monate in Mitteleuropa als Hilfsmittel für die synoptische Interpretation analoger Anomalien im historischen Klima und in zukünftigen Klimaszenarien', Petermanns Geographische Mitteilungen 141, 139-144.

Jones, P.D.: 1996, 'A la Recherche du Temps Perdu', Nature 381, 375-376.

Jones, P.D., Davies, T.D., Lister, D.H., Slonosky, V., Jónsson, T., Bärring, L., Jönsson, P.,Maheras, P., Kolyva-Machera, F., Barriendos, M., Martin-Vide, J., Rodriguez, R., Alcoforado, M.J., Wanner, H., Pfister, C., Luterbacher, J., Rickli, R., Schuepbach, E., Kaas, E., Schmith, T., Jacobeit, J. and Beck, C.: 1999, 'Monthly Mean Pressure Reconstructions for Europe for the 1780-1995 period, Int. J. Climat. (in press).

Koslowski, G. and Loewe, P.: 1994, 'The Western Baltic Sea Ice Season in Terms of a Mass-Related Severity Index 1879-1992. Part I: Temporal Variability and Association With the North Atlantic Oscillation', Tellus 46A, 66-74.

Koslowski, G. and Glaser, R.: 1999, 'Variations in Reconstructed Ice Winter Severity in the Western Baltic from 1501 to 1995, and their Implications for the North Atlantic Oscillation', Climatic Change (in press).

Lamb, P.J. and Peppler, R.A.: 1987, 'North Atlantic Oscillation: Concept and Application', Bull. Amer. Meteor. Soc. 68, 1217-1225.

Lean, J. and Rind, D.: 1996, 'The Sun and Climate - Consequences', The Nature and Implications of Environmental Change 2, 27-36.

Moses, T., Kiladis, G.N., Diaz, H.F. and Barry, R.G.: 1987, 'Characteristics and Frequency of Reversals in Mean Sea Level Pressure in the North Atlantic Sector and their Relationship to Long-Term Temperature Trends', $J$. Climat. 7, 13-30.

Palmer, T.N. and Sun, Z.: 1985, 'A Modelling and Observational Study of the Relationship between Sea Surface Temperature in the North-West Atlantic and the Atmospheric Circulation', $Q u-$ art. J. Roy. Met. Soc. 111, 947-975.

Pfister, C., Kington, J., Kleinlogel, G., Schüle, H. and Siffert, E.: 1994, 'High Resolution SpatioTemporal Reconstructions of Past Climate from Direct Meteorological Observations and Proxy Data', Paleoclimate Research 13, 329-375.

Pfister, C.: 1995, 'Monthly Temperature and Precipitation in Central Europe from 1525-1979: Quantifying Documentary Evidence on Weather and its Effects', in Bradley, R.S. and Jones, P.D. (eds.), Climate Since A.D. 1500, Routledge, London and New York, pp. 118-142.

Simkin, T., Siebert, L., McClelland, L., Bridge, D., Newhall, C. and Latter, J.H.: 1981, Volcanoes of the World. Hutchinson Ross, Stroudsberg, Penn., $233 \mathrm{pp}$.

Stocker, T.F.: 1996, 'An Overview of Century Time-Scale Variability in the Climate System: Observations and Models', NATO ASI Series, Vol. I 44, 379-406.

Stuiver, M. and Braziunas, T.F.: 1995, 'Evidence of Solar Activity Variations', in Bradley, R.S. and Jones, P.D. (eds.), Climate Since A.D. 1500, Routledge, London and New York, pp. 606622.

Van Loon, H. and Rogers, J.C.: 1978, 'The Seesaw in Winter Temperatures Between Greenland and Northern Europe. Part I: General Description', Mon. Wea. Rev. 106, 296-310.

Walker, G.T.: 1924, 'Correlations in Seasonal Variations of Weather', IX. Mem. Indian Meteor. 
Dept. 24, 275-332.

Wanner, H., Brázdil, R., Frich, P., Frydendahl, K., Jónsson, T., Kington, J., Pfister, C., Rosenørn, S. and Wishman, E.: 1994, 'Synoptic Interpretation of Monthly Weather Maps for the Late Maunder Minimum (1675-1704)', Paleoclimate Research 13, 401-424.

Wanner, H., Pfister, C., Brázdil, R., Frich, P., Frydendahl, K., Jonsson, T., Kington, J., Lamb, H.H., Rosenørn, S. and Wishman, E.: 1995, 'Wintertime European Circulation Patterns during the Late Maunder Minimum Cooling Period (1675-1704)', Theor. Appl. Climatol. 51, 159-165.

Wanner, H., Rickli, R., Salvisberg, E., Schmutz, C. and Schuepp, M.: 1997, 'Global Climate Change and Variability and its Influence on Alpine Climate - Concepts and Observations', Theor. Appl. Climatol. 57, 132-156. 